Historic, Archive Document

Do not assume content reflects current scientific knowledge, policies, or practices. 



\title{
A99.9 \\ Taxonomy and Effects of Dwarf Mistletoe on Bristlecone Pine on the San Francisco Peaks, Arizona
}

\author{
Robert L. Mathiasen and Frank G. Hawksworth
}

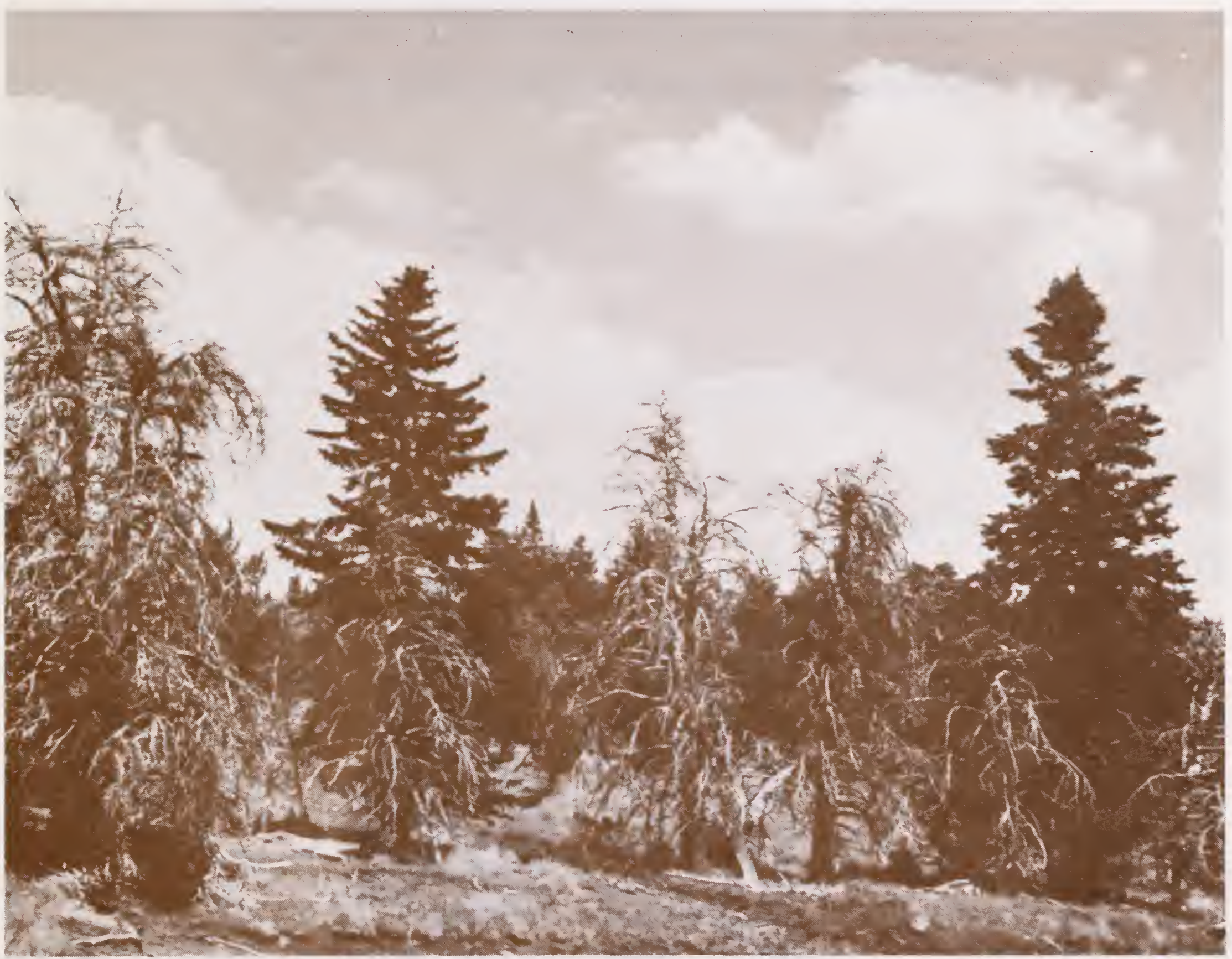

Research Paper RM-224

Rocky Mountain Forest and

Range Experiment Station

Forest Service

U.S. Department of Agriculture 


\section{0}

Abstract

The dwarf mistletoe parasitizing bristlecone pine on the San Francisco Peaks, Arizona, is shown to be Arceuthobium microcarpum, instead of A. cyanocarpum as reported previously. The dwarf mistletoe caūses serious localized damage, but it is not considered to be a serious threat to the bristlecone pine population. "

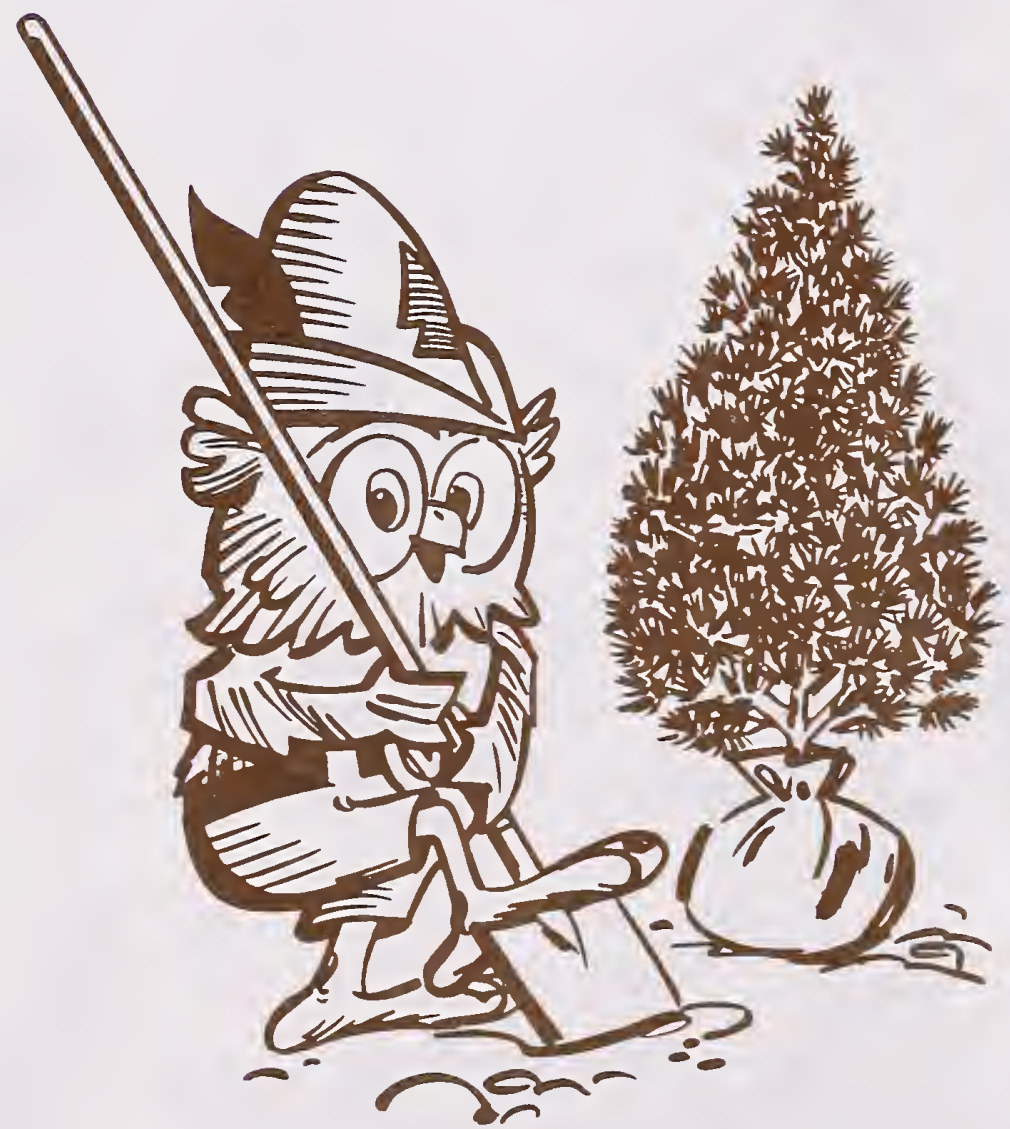

Plant a tree! Mark the 75th birthday of the Forest Service by giving a living gift to future generations. 


\title{
Taxonomy and Effects of Dwarf Mistletoe on Bristlecone Pine on the San Francisco Peaks, Arizona ${ }^{1}$
}

\author{
Robert L. Mathiasen, Research Associate \\ Department of Plant Pathology \\ University of Arizona, Tucson \\ and \\ Frank G. Hawksworth, Forest Pathologist \\ Rocky Mountain Forest and Range Experiment Station ${ }^{2}$
}




\section{Contents}

Page

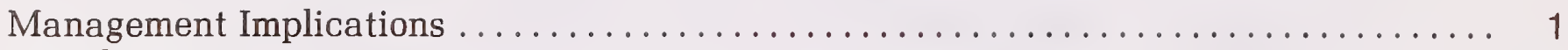

Introduction ........................................... 1

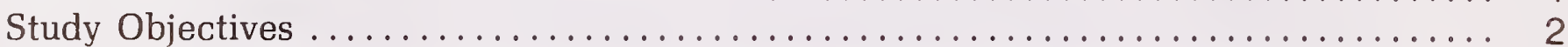

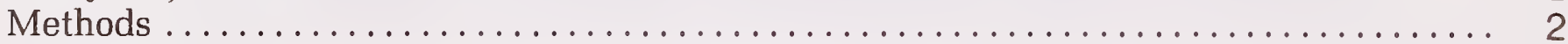

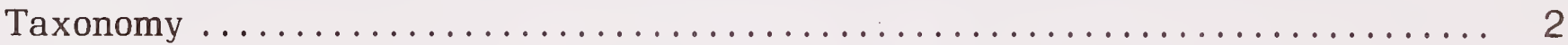

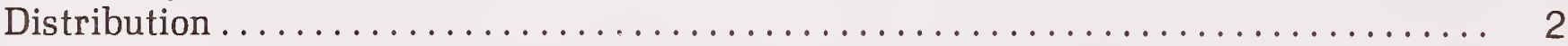

Hosts ............................................. 2

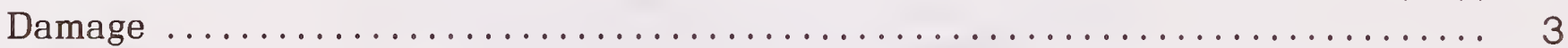

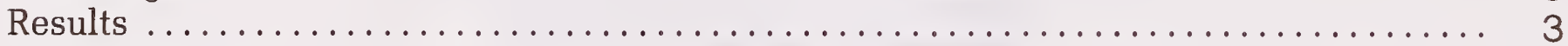

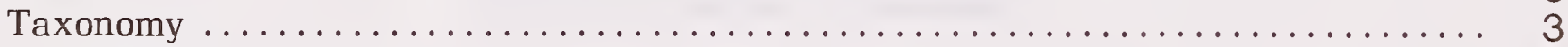

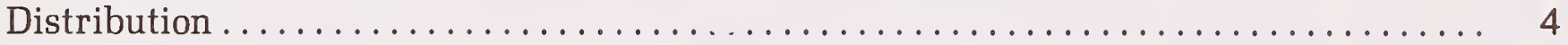

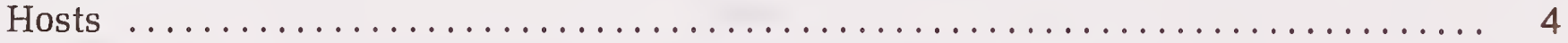

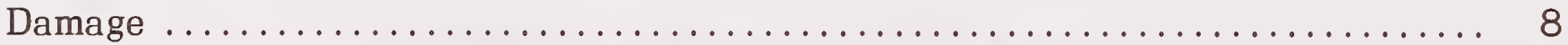

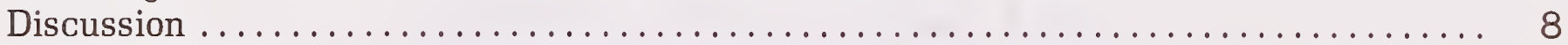

Literature Cited ..................................... 9

Appendix —Common and Scientific Names of Trees ..................... 10 


\title{
$2 i 4$ \\ Taxonomy and Effects of Dwarf Mistletoe $\tau^{\prime}=$ on Bristlecone Pine $\sqsubset \frac{2}{3}$ on the San Francisco Peaks, Arizona
}

\author{
Robert L. Mathiasen and Frank G. Hawksworth
}

\section{Management Implications} Rocky Mountain bristlecone pine [Pinus aristata]
Engelm.) is found in many of the higher mountain ranges in Colorado and northern New Mexico. In Arizona, however, this species is found only on the San Francisco Peaks near Flagstaff. Bristlecone pine is the predominant species on only about 3,400 acres $(1,360$ ha) of the San Francisco Peaks. Bristlecone pine is considered as an endangered species in Arizona and, because of its rarity in the state, it is protected by the Arizona Native Plant Law (McDougall 1975).

A dwarf mistletoe parasitizing bristlecone pine on the San Francisco Peaks was discovered as early as 1901, but its taxonomic status, distribution, and impact on the bristlecone pine population there has remained uncertain. In 1973, we discovered a heavily mistletoeinfested bristlecone pine stand with considerable mortality on the south slopes of the San Francisco Peaks.
Morphological and physiological characteristics of the bristlecone pine dwarf mistletoe indicate it is Arceuthobium microcarpum (Engelm.) Hawksw. \& Wiens. Only about $12 \%$ of the total area occupied by bristlecone pine on the San Francisco Peaks is infested. Noninfested bristlecone pine stands are now generally isolated from the infested stands by nonsusceptible species. In addition, A. microcarpum has an upper elevational limit well below that of bristlecone pine on the San Francisco Peaks and most of the bristlecone pine occurs above this limit. Therefore, although $A$. microcarpum is causing localized damage to bristlecone pine on the San Francisco Peaks, we do not consider the mistletoe to be a serious threat to this bristlecone pine population and do not consider control measures to be necessary.

\section{Introduction}

The classification of the dwarf mistletoe parasitizing bristlecone pine on the San Francisco Peaks, Arizona, has been uncertain since specimens were first collected by J. B. Leiberg in 1901. Gill (1935) classified the mistletoe as Arceuthobium campylopodum] forma cyanocarpum (A. Nels.) Gill. Hawksworth and Wiens (1970, 1972ł raised Gill's host form cyanocarpum to specific rank, based on its morphology, phenology, and host specificity. Hawksworth and Wiens (1972) tentatively identified the bristlecone pine dwarf mistletoe on the San Francisco Peaks as the limber pine dwarf mistletoe (A. cyanocarpum Coulter \& Nelson), but noted that additional taxonomic studies were needed before a positive identification could be made. Comparison of the flavonoid constituents from shoots of the San Francisco Peaks bristlecone pine dwarf mistletoe with those of other species of Arceuthobium indicated the bristlecone pine dwarf mistletoe was most similar to the western spruce dwarf mistletoe (A. microcarpum) (Crawford and Hawksworth 1979).
Relatively little information on the effect of the San Francisco Peaks bristlecone pine dwarf mistletoe or its host range has been available until recently. The principal hosts of $A$. cyanocarpum are limber pine, whitebark pine, Great Basin bristlecone pine, and, rarely, Rocky Mountain bristlecone pine (Hawksworth and Wiens 1972). Hawksworth (1965) reported that bristlecone pine was the only host of the bristlecone pine dwarf mistletoe on the San Francisco Peaks, but Hawksworth and Wiens (1972) reported four additional hosts. Engelmann spruce and blue spruce were occasional hosts, and corkbark fir and southwestern white pine were rare hosts. It is now thought, however, that there is no blue spruce on the San Francisco Peaks and that the infected trees reported by Hawksworth and Wiens (1972) were somewhat aberrant Engelmann spruces. $^{3}$ Subsequent observations have failed to substantiate the report of blue spruce on the San Fran-

${ }^{3} J$. R. Jones, personal communication, 1976, formerly silviculturist, Rocky Mountain Forest and Range Experiment Station, Flagstaff, Ariz. 
cisco Peaks, but indicated Engelmann spruce and bristlecone pine were more severely and commonly affected by the bristlecone pine dwarf mistletoe than originally believed.

Other dwarf mistletoes on the San Francisco Peaks are A. douglasii Engelm. on Douglas-fir and corkbark fir, A. divaricatum Engelm. on pinyon, A. vaginatum subsp. cryptopodum (Engelm.) Hawksw. \& Wiens on ponderosa pine, and A. microcarpum on Engelmann spruce (Hawksworth and Wiens 1972). Bristlecone pine is also susceptible to $A$. microcarpum as demonstrated by artificial inoculations (Mathiasen 1978).

\section{Study Objectives}

This investigation was undertaken to clarify the taxonomic status of the bristlecone pine dwarf mistletoe, describe the distribution of the mistletoe on the San Francisco Peaks, identify the hosts of the mistletoe and their relative susceptibility, and determine the potential importance of the mistletoe to this local population of bristlecone pine.

\section{Methods}

\section{Taxonomy}

Morphological characters of the San Francisco Peaks' bristlecone pine dwarf mistletoe were compared with those of $A$. cyanocarpum and $A$. microcarpum. Measurements and observations of the bristlecone pine dwarf mistletoe were made from 19 specimens collected in 1975 from the San Francisco Peaks and from 5 specimens previously deposited at the USDA Forest Service, Forest Pathology Herbarium, Fort Collins, Colo. (FPF). Measurements of shoot height of $A$. cyanocarpum were made from 43 specimens collected throughout its geographic range. All other morphological data for $A$. cyanocarpum were taken from Hawksworth and Wiens (1972). Measurements and observations for A. microcarpum were made from 26 specimens collected throughout its geographic range in 1975 and 1976 and from 20 specimens previously deposited at FPF.

The following morphological characters were recorded: height, basal diameter, color, and growth habit of dominant male and female shoots (nonsystemic infections only); staminate flower diameter; number, length, width, and color of perianth lobes; length, width, color of the distal end, and length of the proximal end of mature fruit; and length, width, and color of mature seed. In addition, the northern (North Rim Grand Canyon, Kendrick Peak, and San Francisco Peaks, Arizona) and southern populations (White and Pinaleno Mountains, Arizona, and Mogollon Mountains, New Mexico) of A. microcarpum were analyzed separately.
Observations of flowering and seed dispersal were made in the summer and fall of 1973 through 1976 for the bristlecone pine dwarf mistletoe and A. microcarpum throughout their geographic ranges. The species of mistletoe, location, and date were recorded for each field observation, and flowering and seed dispersal were classed as not started, started but not near peak, near peak, past peak but not completed, or completed. Phenology data were summarized for all observations from July 1 through November 2. Results were compared with the flowering and seed dispersal periods of A. cyanocarpum (Hawksworth and Wiens 1972).

Since there are qualitative chemical differences among species of Arceuthobium (Hawksworth and Wiens 1972, Crawford and Hawksworth 1979), three collections of the bristlecone pine dwarf mistletoe, four collections of A. microcarpum, and one collection of A. cyanocarpum were analyzed chromatographically following the methods described by Hawksworth and Wiens (1972). All samples were analyzed in the first dimension only, and anthocyanins were not considered. Results were compared with those obtained for $A$. cyanocarpum and $A$. microcarpum by Hawksworth and Wiens (1972).

\section{Distribution}

The distribution of the bristlecone pine dwarf mistletoe was determined by reconnaissance surveys made in 1974 and 1975 of the larger and most of the smaller stands of bristlecone pine on the San Francisco Peaks. Kendrick Peak, approximately 15 miles to the west, was also examined for bristlecone pine. The approximate distribution of bristlecone pine and the geographic and elevational limits of the bristlecone pine dwarf mistletoe were recorded on topographic maps of the area (Humphrey's Peak and Sunset Crater West, Coconino County, Arizona, United States Geological Survey, 1966, 7.5 series). The approximate acreage of bristlecone pine and mistletoe-infested areas was estimated using a planimeter.

\section{Hosts}

Hawksworth and Wiens (1972) established five natural susceptibility classes based on the percentage of trees infected within 20 feet of heavily infected hosts of dwarf mistletoe. These were: principal (90\% to $100 \%$ ), secondary ( $50 \%$ to $90 \%$ ), occasional (5\% to $50 \%)$, rare $(0 \%$ to $5 \%)$, and immune. General field observations for susceptible hosts of the bristlecone pine dwarf mistletoe were made on the San Francisco Peaks from 1973 through 1976. Specimens representing the different host-parasite combinations observed were collected and deposited at FPF.

In addition, all conifers over 4 inches d.b.h. were examined in 27 random 0.25 - or 0.50 -acre rectangular plots totaling 10 acres within the infested bristlecone 
pine stands on the San Francisco Peaks. the host species, dwarf mistletoe rating (DMR, 6-class system) (Hawksworth 1977), and condition (living or dead) of each tree were recorded. Observations were also made on an additional 13 randomly placed plots totaling 5 acres in noninfested bristlecone pine stands. Dead trees were randomly examined for signs of secondary pathogens and insects.

\section{Damage}

The effect of dwarf mistletoe on bristlecone pine on the San Francisco Peaks was assessed by comparing the mortality rates of infested and noninfested bristlecone pine stands. Mortality rates for bristlecone pine were also calculated on the basis of average plot mistletoe ratings for four mistletoe infection classes. Mistletoe-infested bristlecone pine acreage was also considered as a factor in assessing the effect of the dwarf mistletoe on the bristlecone pine population.

\section{Results}

\section{Taxonomy}

Analysis of morphological, physiological, and chemical characters of the bristlecone pine dwarf mistletoe indicate it is $A$. microcarpum, not $A$. cyanocarpum. Morphologically, the bristlecone pine dwarf mistletoe is most similar to A. microcarpum in shoot and fruit color, shoot height, fruit, flower, and seed size (table 1). Flowering and seed dispersal periods of the bristlecone pine dwarf mistletoe were approximately the same as those of $A$. microcarpum, while $A$. cyanocarpum flowers and disperses seed earlier (fig. 1). All three dwarf mistletoes were similar chromatographically, but $A$. cyanocarpum consistently lacked two flavonol bands present in both $A$. microcarpum and the bristlecone pine dwarf mistletoe.

Analysis of morphological and physiological characters of the northern and southern populations of $A$. microcarpum indicates differences between these

Table 1.-Comparison of morphological characters of the bristlecone pine dwarf mistletoe,

A. microcarpum and A. cyanocarpum

\begin{tabular}{|c|c|c|c|}
\hline Character & A. microcarpum ${ }^{1}$ & $\begin{array}{l}\text { Bristlecone pine } \\
\text { dwarf mistletoe }\end{array}$ & A. cyanocarpum ${ }^{2}$ \\
\hline Mean shoot height $(\mathrm{cm})$ & 4 & 4 & 3 \\
\hline Mean shoot diameter (mm) & 1.9 & 2.1 & 1.4 \\
\hline Mean fruit length (mm) & 3.1 & 3.1 & 3.5 \\
\hline \multicolumn{4}{|l|}{ Mean staminate flower } \\
\hline width $(\mathrm{mm})$ & 2.2 & 2.5 & 3.0 \\
\hline Mean seed length $(\mathrm{mm})$ & 2.4 & 2.4 & 2.0 \\
\hline $\begin{array}{l}\text { Color (shoot distal end } \\
\text { of fruit) }\end{array}$ & $\begin{array}{l}\text { green to purple } \\
\text { to brownish-green } \\
\text { to reddish }\end{array}$ & $\begin{array}{l}\text { green to purple } \\
\text { to brownish-green } \\
\text { to reddish }\end{array}$ & $\begin{array}{l}\text { yellow-green to } \\
\text { reddish-green }\end{array}$ \\
\hline
\end{tabular}

${ }^{1}$ Northern population (see table 2).

${ }^{2}$ From Hawksworth and Wiens (1972).
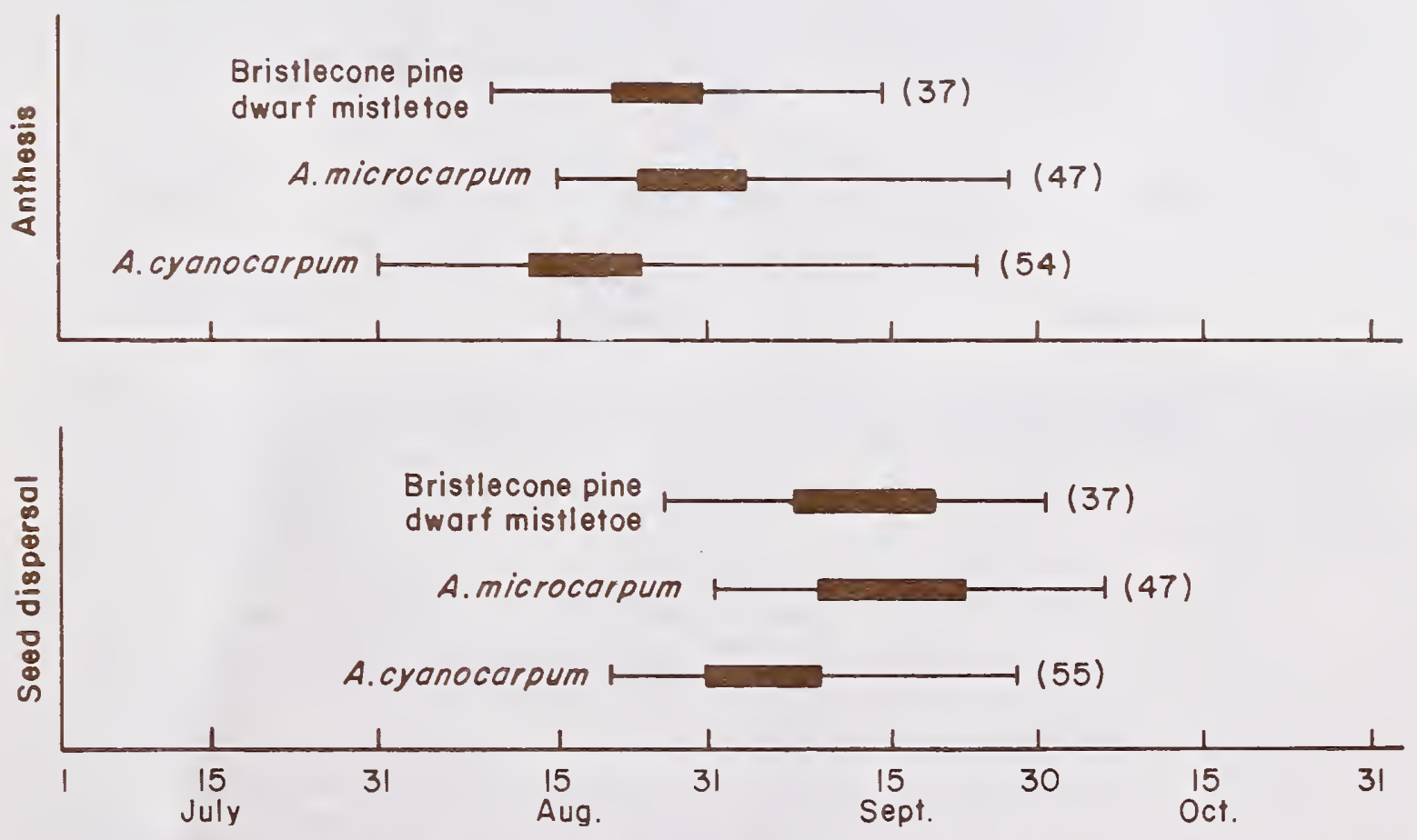

Figure 1.-Approximate periods of anthesis and seed dispersal of bristlecone pine dwarf mistletoe, $\boldsymbol{A}$. cyanocarpum and $\boldsymbol{A}$. microcarpum. Peak periods are shown by solid bars; number of observations are shown in parentheses. 
populations (table 2). Shoots are larger in the southern populations and their flowering period occurs slightly later. Hawksworth and Wiens (1972) reported that southwestern white pine was immune to $A$. microcarpum. However, we found that $A$. microcarpum rarely parasitizes this tree on the San Francisco Peaks. Subsequent reconnaissance surveys in the southern populations of $A$. microcarpum did not detect infected southwestern white pines, although this tree is common in infested spruce stands.

\section{Distribution}

Our reconnaissance surveys indicate bristlecone pine is the predominant species on approximately 3,400 acres $(1,360$ ha) of the San Francisco Peaks (fig. 2 ). The tree is primarily distributed on the south side of the Peaks between 9,000 and 11,800 feet $(2,700$ and $3,600 \mathrm{~m}$ ), and its main associates are Engelmann spruce and corkbark fir. Minor associates are Douglasfir, southwestern white pine, quaking aspen, and very rarely, ponderosa pine and pinyon. Bristlecone pine was not found on Kendrick Peak.

Three populations of $A$. microcarpum were detected on bristlecone pine on the San Francisco Peaks (fig. 2). The largest population (approximately 350 acres) is near Schultz Peak (T. $22^{\circ}$ N., R. $7^{\circ}$ E., sec. 2, 3, 10, and 11) and contains large numbers of dead bristlecone pines (fig. 3). A second population (approximately 50 acres) is one-half mile due west of Schultz Peak (T. $22^{\circ}$ N., R. $7^{\circ}$ E., sec. 3 and 10 ), and is not continuous with the larger population. The third population consists of ten infected bristlecone pines in the Inner Basin approximately 1.5 miles $(2 \mathrm{~km})$ north of Schultz Peak (T. $23^{\circ}$ N., R. $7^{\circ}$ E., sec. 27). The 10 trees are close to Engelmann spruces heavily infected with $\mathrm{A}$. microcarpum. Thus, about 400 acres (160 ha) or $12 \%$ of the total area dominated by bristlecone pine on the San Francisco Peaks, is affected by dwarf mistletoe.
A. microcarpum occurs as low as 9,100 feet $(2,700 \mathrm{~m})$ and as high as 10,300 feet $(3,100 \mathrm{~m})$ on ridges running southeast and north from Schultz Peak, respectively (fig. 2). It does not extend above 10,300 feet near Schultz Peak or in the Inner Basin, although bristlecone pine and Engelmann spruce occur continuously to higher elevations in both of these areas.

\section{Hosts}

Bristlecone pine is the principal host of A. microcarpum in the infested stands near Schultz Peak. Engelmann spruce is also parasitized by A. microcarpum in the vicinity of Schultz Peak, but not as severely as bristlecone pine. The following infection percentages were obtained from the 27 plots placed in the infested bristlecone pine stands around Schultz Peak:

\section{Tree species}

Bristlecone pine

Engelmann spruce

Corkbark fir

Southwestern white pine Douglas-fir

Pinyon

\section{Number of trees Percent examined infected}

$\begin{array}{rr}1,404 & 84 \\ 608 & 32 \\ 185 & 5 \\ 317 & 1 \\ 87 & 0 \\ 5 & 0\end{array}$

Observations in the Schultz Peak area indicate approximately $50 \%$ to $80 \%$ of the Engelmann spruce near heavily infected bristlecone pines are infected. Therefore, Engelmann spruce is classified as a secondary host of $A$. microcarpum in that area. Infection levels are much higher for Engelmann spruce in the Inner Basin where spruce is the principal host of $A$. microcarpum. Differences in host response were observed for infected Engelmann spruce in the two different areas also. In the Schultz Peak area, witches'

Table 2.-Comparison of the northern and southern populations of A. microcarpum

\begin{tabular}{|c|c|c|}
\hline Character & $\begin{array}{l}\text { Northern } \\
\text { population }\end{array}$ & $\begin{array}{l}\text { Southern } \\
\text { population }\end{array}$ \\
\hline $\begin{array}{l}\text { Number of specimens examined } \\
\text { Shoot height, mean and range }(\mathrm{cm})\end{array}$ & 37 & 20 \\
\hline Pistillate & $3.0-7.0$ & $4.0-12.0$ \\
\hline Staminate & $1.5-7.0$ & $3.0 \cdot 13.0$ \\
\hline Basal diameter mean and range $(\mathrm{mm})$ & $0.8-2.4$ & $1.0-3.0$ \\
\hline Principal hosts & $\begin{array}{l}\text { Bristlecone pine } \\
\text { Engelmann spruce } \\
\text { Blue spruce }\end{array}$ & $\begin{array}{l}\text { Engelmann spruce } \\
\text { Blue spruce }\end{array}$ \\
\hline Rare hosts & $\begin{array}{l}\text { Southwestern white pine } \\
\text { Corkbark fir }\end{array}$ & Corkbark fir \\
\hline Immune species & $\begin{array}{l}\text { White fir } \\
\text { Ponderosa pine } \\
\text { Douglas-fir } \\
\text { Subalpine fir }\end{array}$ & $\begin{array}{l}\text { White fir } \\
\text { Ponderosa pine } \\
\text { Douglas-fir } \\
\text { Southwestern white pine }\end{array}$ \\
\hline
\end{tabular}

'North Rim, Grand Canyon; Kendrick Peak and San Francisco Peaks, Arizona.

${ }^{2}$ White Mountains and Pinaleno Mountains, Arizona, and Mogollon Mountains, New Mexico. 


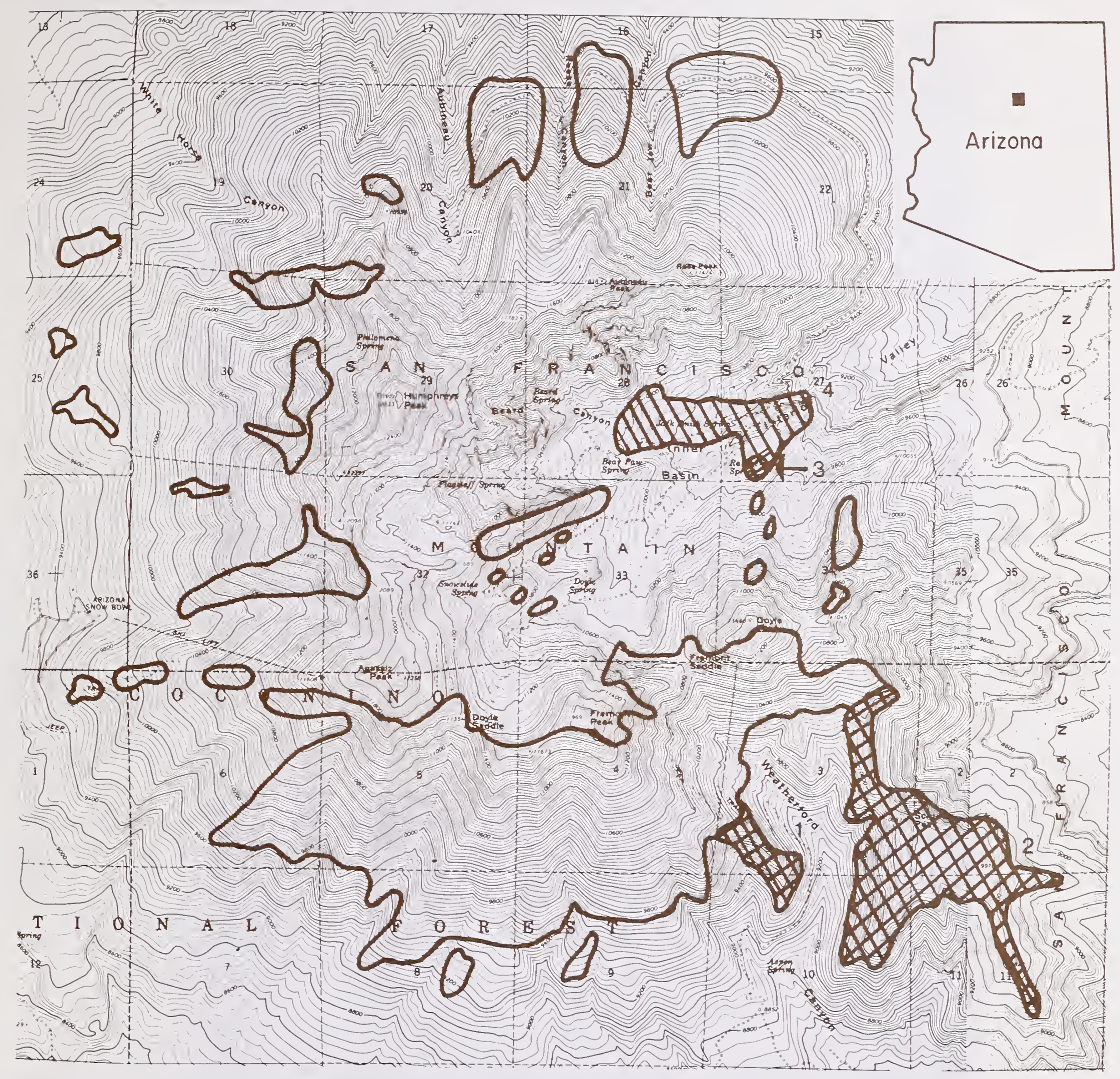

Figure 2.-Approximate distribution of bristlecone pine A. microcarpum, and the bristlecone pine dwarf mistletoe on the San Francisco Peaks, Arizona. Areas encircled by dark lines represent bristlecone pine. Checkered areas $(1$ to 3 ) represent the bristlecone pine dwarf mistletoe. Crossed area (4) represents $A$. microcarpum on spruce with scattered populations of healthy bristlecone pine.

brooms are generally dense and round with unusually large stem swellings. In the Inner Basin and elsewhere, witches' brooms are commonly "flat" and less dense without large branch swellings.

Southwestern white pine and corkbark fir are rare hosts of A. microcarpum near Schultz Peak, but frequent observations of these species in the infested Inner Basin stands did not detect infected trees. Of several hundred trees examined for A. microcarpum (near Schultz Peak), only 11 infected southwestern white pines and 12 infected corkbark firs were discovered. Abundant shoot production is characteristic of infections on bristlecone pine (fig. 4), but few shoots are produced on infected southwestern white pines and corkbark firs (figs. 5 and 6). Small, nonsystemic witches' brooms and abnormally large stem swellings result from infection by $A$. microcarpum on both of these rare hosts. 


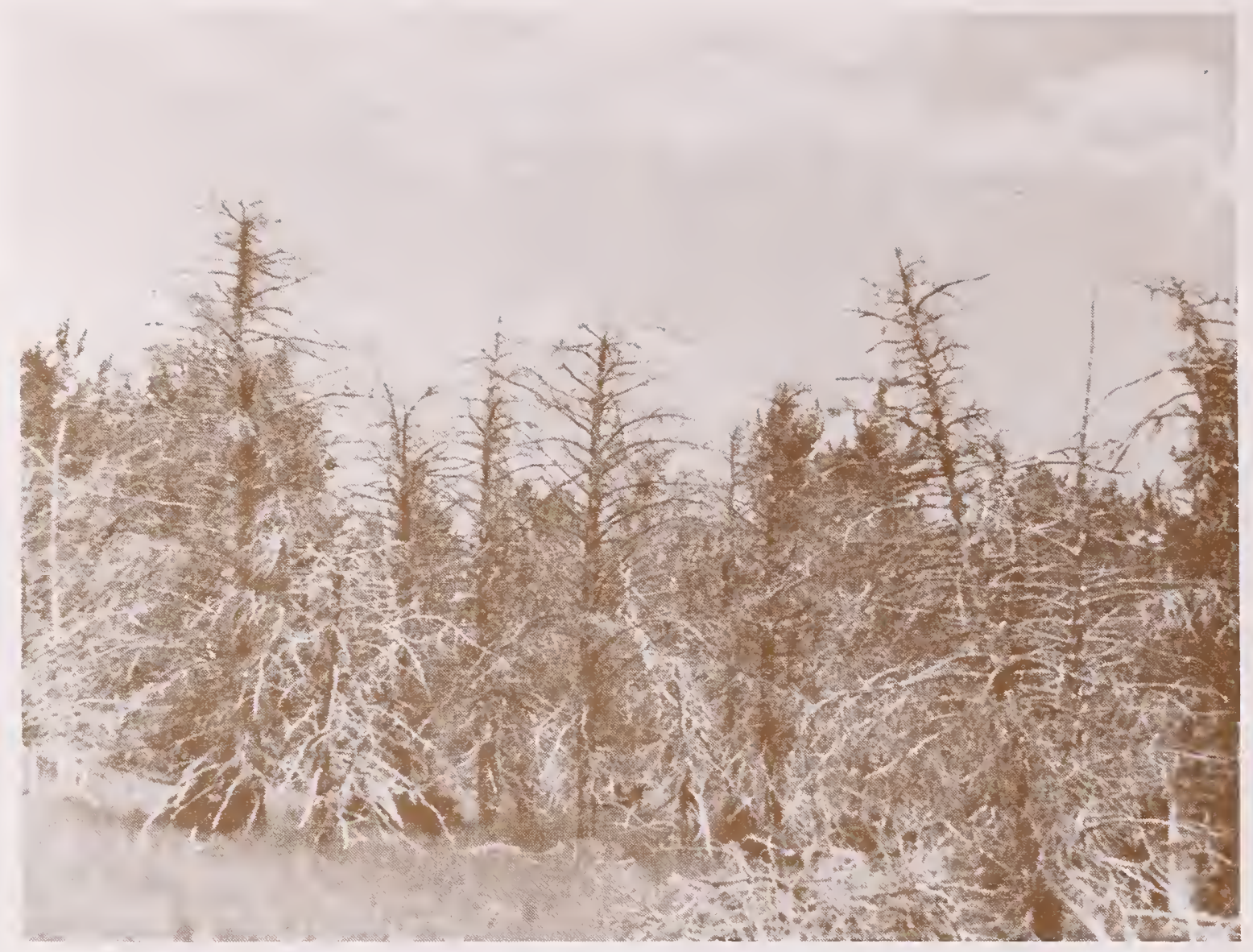

Figure 3.-Bristlecone pine mortality resulting from infection by A. microcarpum on the San Francisco Peaks.

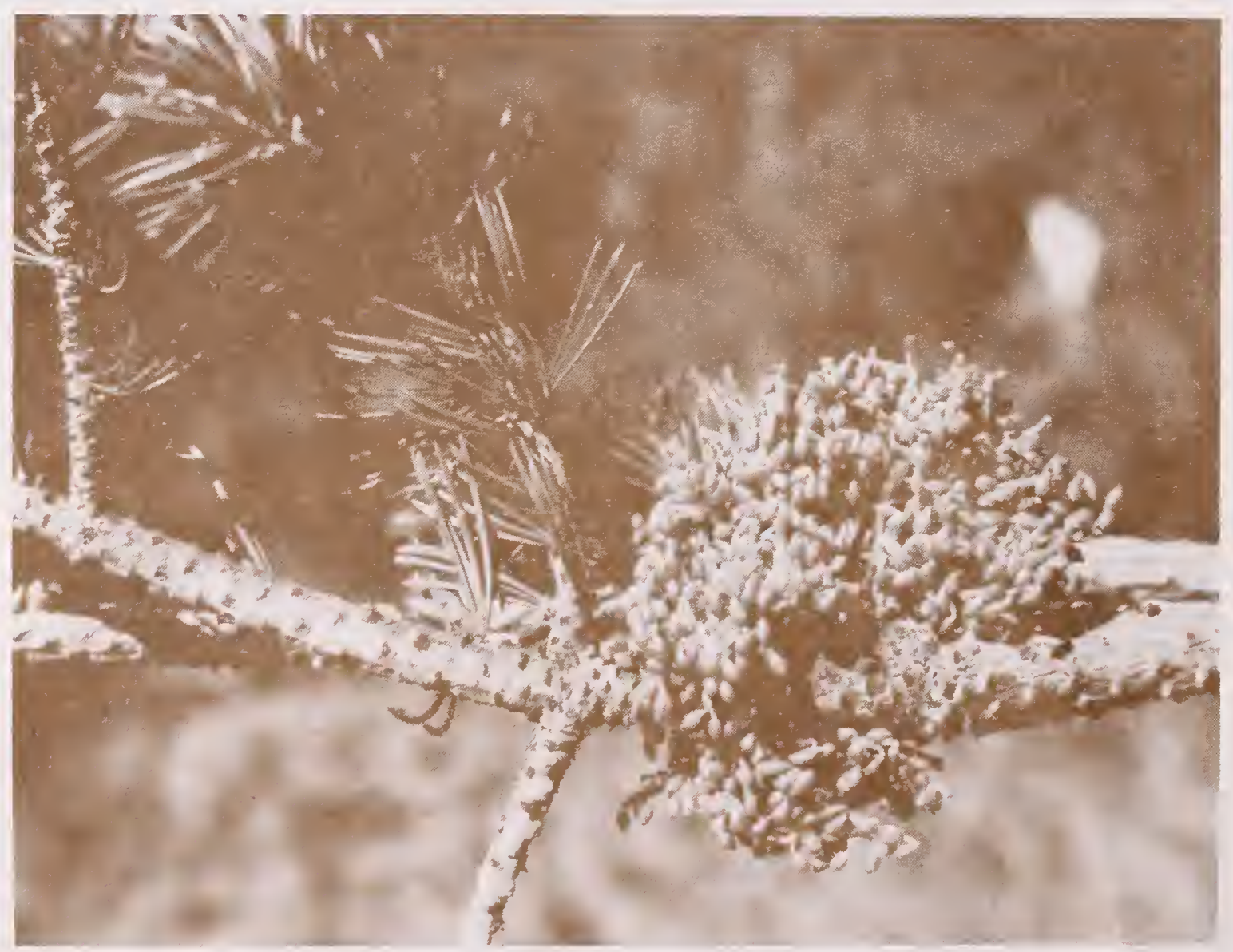

Figure 4. - Shoots of A. microcarpum on bristlecone pine (pistillate shoots). 


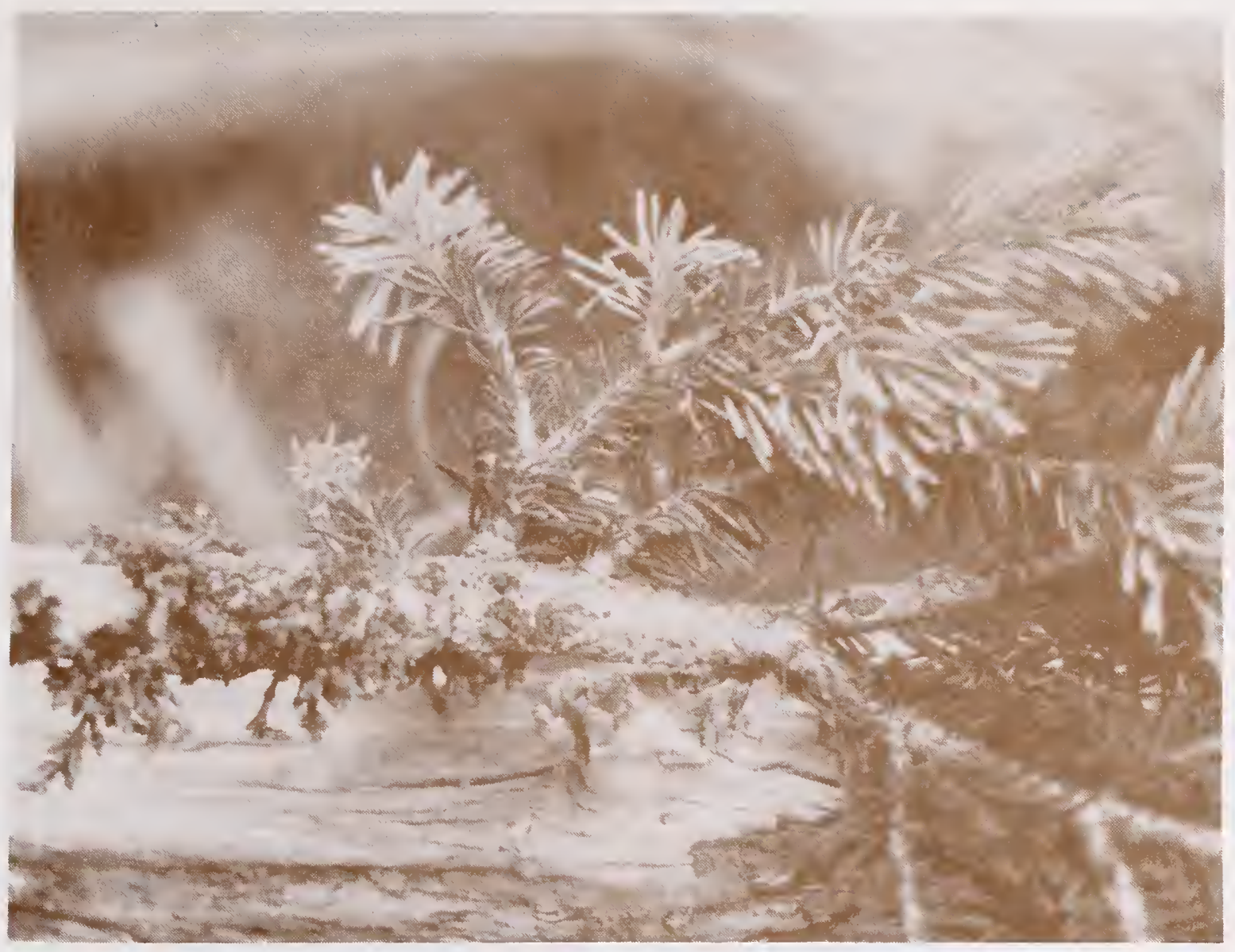

Figure 5. - A. microcarpum on corkbark fir, a rare host. Note the large fusilform swelling and poor shoot production.

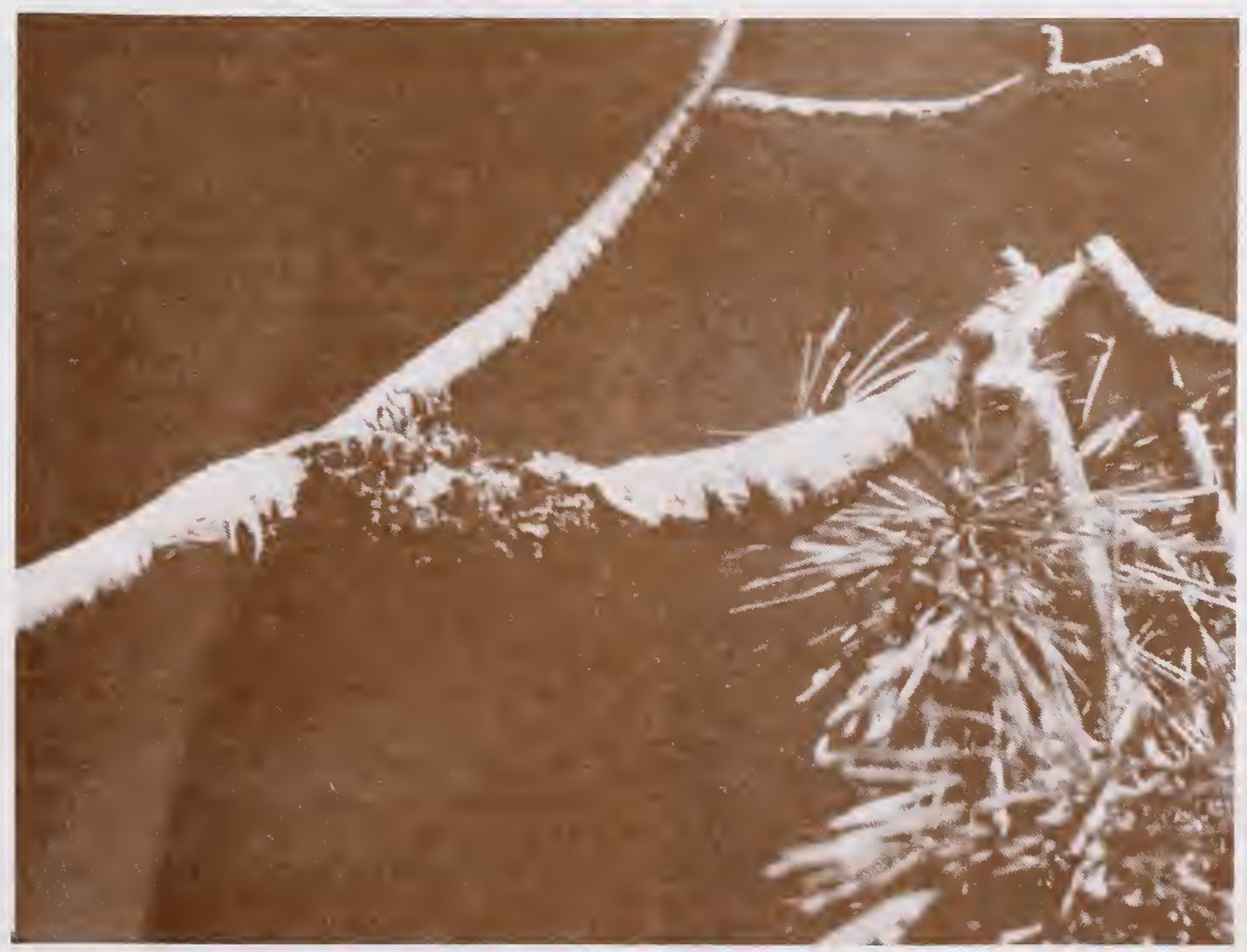

Figure 6.-A. microcarpum on southwestern white pine, a rare host. 
Douglas-fir is immune to A. microcarpum; no infected Douglas-firs were found among heavily infected bristlecone pines. A few infected Douglas-firs were found near Schultz Peak, but examination of the mistletoe on these trees indicated that they were infected by $A$. douglasii (Hawksworth and Wiens 1972). A few trees each of white fir, ponderosa pine, and pinyon were observed near heavily infected bristlecone pines, but none were infected.

\section{Damage}

Mortality counts indicate that approximately $37 \%$ of the standing bristlecone pines are dead in the dwarf mistletoe infested areas near Schultz Peak. Most of the dead bristlecone pines had large witches' brooms indicative of mistletoe infection (fig. 7). No other primary pathogens or insects were detected in the dead trees. Mortality of bristlecone pine in the noninfested areas sampled was one-sixth of that in the mistletoe-infested stands. Mortality rates of bristlecone pine were also calculated on the basis of average plot mistletoe ratings for four mistletoe infection classes as a percentage of the total number of standing trees examined. The results show that mortality is related to the severity of mistletoe infection:

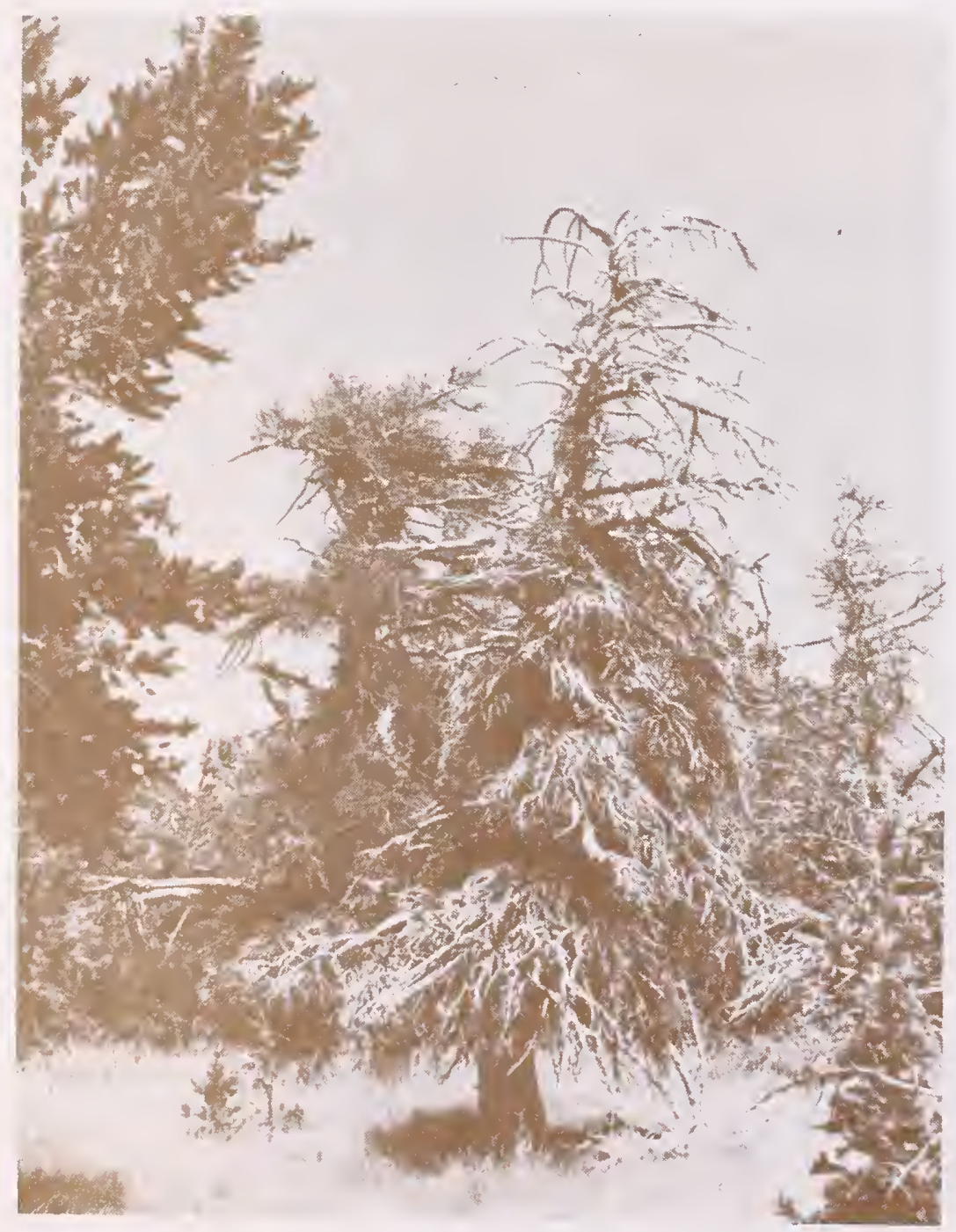

Figure 7.-A dead, heavily mistletoe-infected bristlecone pine.
Level of infection

Stand basis

Noninfested

(DMR 0)

Lightly infested

(DMR 0.1-2.0)

Moderately infested

(DMR 2.1-4.0)

Heavily infested

(DMR 4.1-6.0)
Bristlecone pine mortality

percent

40.6

\section{Discussion}

Results of analysis of morphological, physiological, and chemical characters of the San Francisco Peaks bristlecone pine dwarf mistletoe indicate it is A. microcarpum, and not $A$. cyanocarpum as suggested by Hawksworth and Wiens (1972). The susceptibility of bristlecone pine to A. microcarpum as demonstrated in artificial inoculation trials (Mathiasen 1978) and Crawford and Hawksworth's (1979) comparison of flavonoid compounds found in dwarf mistletoe shoots also supports the classification of the bristlecone pine dwarf mistletoe as A. microcarpum.

Ecological evidence also lends support to the classification of the San Francisco Peaks bristlecone pine dwarf mistletoe as A. microcarpum. The upper elevational limit of the mistletoe on the San Francisco Peaks is the same as that reported for A. microcarpum in the White Mountains, Arizona (Acciavatti and Weiss 1974). The reasons for a distinct elevational limit are unclear, but are probably climatic. Hawksworth (1956, 1969) reported an upper elevational limit for the lodgepole pine dwarf mistletoe (A. americanum Nutt. ex Engelm.) which was several hundred feet below the upper elevational limit of its principal host in the central Rocky Mountains. Hawksworth (1969) suggested that fruits of $A$. americanum may not mature at elevations above its natural limits because of the shortness of the growing season. A similar situation may be responsible for the absence of $A$. microcarpum above 10,400 feet $(3,700 \mathrm{~m})$ in Arizona and possible for its absence from the extensive stands of Engelmann spruce in the central and northern Rocky Mountains.

Morphological and physiological differences between the southern and northern populations of $A$. microcarpum may represent genetic variation, or the influence of environmental and/or host variation. Latitudinal and/or elevational differences may be influencing both shoot height and flowering in these populations. Although the differences between these populations appear to be geographically consistent, we do not believe they are of the magnitude to warrant taxonomic recognition. 
A. microcarpum parasitizes bristlecone pine and Engelmann spruce as principal hosts on the San Francisco Peaks and rarely parasitizes southwestern white pine and corkbark fir there. This is the only reported case of one species of dwarf mistletoe parasitizing four different hosts at a single location. Also, this is only the second reported case in North america of a dwarf mistletoe parasitizing members of two genera as principal hosts (Hawksworth and Wiens 1972, Wass 1976, Smith and Wass 1976).

The differences in host susceptibility and host response between the Schultz Peak population and other populations of $A$. microcarpum may indicate the Schultz Peak population represents a different physiological race. Engelmann and blue spruce are the principal hosts of A. microcarpum throughout most of its geographic range. However, bristlecone pine is the principal host of A. microcarpum around Schultz Peak, and infection of Engelmann spruce in this area is considerably less than in other localities. Mortality rates for Engelmann spruce are low in the Schultz Peak area and its response to infection is abnormal. Infection of corkbark fir by $A$. microcarpum is known from other localities in Arizona (Gill 1935, $\left({ }^{4}\right)$ ), but infection of southwestern white pine is known only from the Schultz Peak area. Further studies are needed, however, to determine if these differences in host responses and susceptibility have taxonomic significance.

The damage to bristlecone pine caused by A. microcarpum on the San Francisco Peaks is very localized. Bristlecone pine mortality is considerably greater in the mistletoe-infested stands when compared to noninfested stands, but the infested areas represent a low percentage of the total acreage dominated by bristlecone pine on the Peaks. The likelihood of $A$. microcarpum spreading into presently noninfested bristlecone pine stands is low because most of these stands are distributed above the upper elevational limits of the mistletoe and because the stands below the limit are separated from the infested stands by areas dominated by nonsusceptible species creating natural buffer zones. Therefore, A. microcarpum does not represent a serious threat to the bristlecone pine stands on the San Francisco Peaks, and management plans for bristlecone pine on the Peaks do not need to include control of $A$. microcarpum.

${ }^{4} R$. L. Mathiasen, unpublished data.

\section{Literature Cited}

Acciavatti, Robert E., and Melvyn J. Weiss. 1974. Evaluation of dwarf mistletoe on Engelmann spruce. Fort Apache Indian Reservation, Arizona. Plant Disease Reporter 58:418-419.

Crawford, Daniel J., and Frank G. Hawksworth. 1979. Flavonoid chemistry of Arceuthobium (Viscaceae). Brittonia 31:212-216.

Gill, L. S. 1935. Arceuthobium in the United States. Transactions of the Connecticut Academy of Arts and Sciences 32:111-245.

Hawksworth, Frank G. 1956. Upper altitudinal limits of lodgepole pine dwarf mistletoe in the central Rocky Mountains. Phytopathology 46:551-562.

Hawksworth, Frank G. 1965. Notes on Arceuthobium on bristlecone pine. Leaflets of Western Botany 10:163-164.

Hawksworth, Frank G. 1969. Ecological aspects of dwarf mistletoe distribution. p. 74-82. In proceedings of the 16th western international forest disease work conference. [Coeur d'Alene, Idaho, October 28November 1, 1968].

Hawksworth, Frank G. 1977. The 6-class dwarf mistletoe rating system. USDA Forest Service General Technical Report RM-48, 7 p. Rocky Mountain Forest and Range Experiment Station, Fort Collins, Colo.

Hawksworth, Frank G., and Delbert Wiens. 1970. New taxa and nomenclatural changes in Arceuthobium (Viscaceae). Brittonia 22:265-269.

Hawksworth, Frank G., and Delbert Wiens. 1972. Biology and classification of dwarf mistletoes (Arceuthobium). U.S. Department of Agriculture, Agricultural Handbook 401, 234 p. Washington, D.C.

Mathiasen, Robert L. 1978. Seed germination and infection techniques for three southwestern dwarf mistletoes. Plant Disease Reporter 62:64-67.

McDougall, W. B. 1975. The problem of endangered plant species in northern Arizona. Plateau 47 (3):8-10.

Smith, R. B., and E. F. Wass. 1976. Field evaluation of ecological differentiation of dwarf mistletoe on shore pine and western hemlock. Canadian Journal of Forest Research 6:225-228.

Wass, E. F. 1976. Ecology of shore pine stands infested with dwarf mistletoe on southeastern Vancouver Island. Canadian Forestry Service, Pacific Forestry Research Centre, Report BC-X-142, 33 p. Victoria, B.C. 


\section{Appendix}

Common and Scientific Names of Trees

Aspen

Blue spruce

Bristlecone pine ${ }^{1}$

Rocky Mountain

Great Basin

Corkbark fir

Douglas-fir,

Rocky Mountain

Engelmann spruce

Limber pine

Lodgepole pine

Pinyon

Ponderosa pine, Rocky Mountain

Southwestern white pine

Subalpine fir

White fir

Whitebark pine
Populus tremuloides Michx.

Picea pungens Engelm.

Pinus aristata Engelm.

Pinus longaeva D. K. Bailey

Abies lasiocarpa

var. arizonica (Merr.)

Lemm.

Pseudotsuga menziesii var. glauca (Beissn.) Franco

Picea engelmannii Parry

Pinus flexilis James

Pinus contorta Dougl.

Pinus edulis Engelm.

Pinus ponderosa var. scopulorum Engelm.

Pinus strobiformis Engelm. Abies lasiocarpa (Hook.) Nutt. var. lasiocarpa

Abies concolor (Gord. et Glend.) Lindl.

Pinus albicaulis Engelm.

'Unless stated otherwise, bristlecone pine as used in this paper refers to Pinus aristata. 


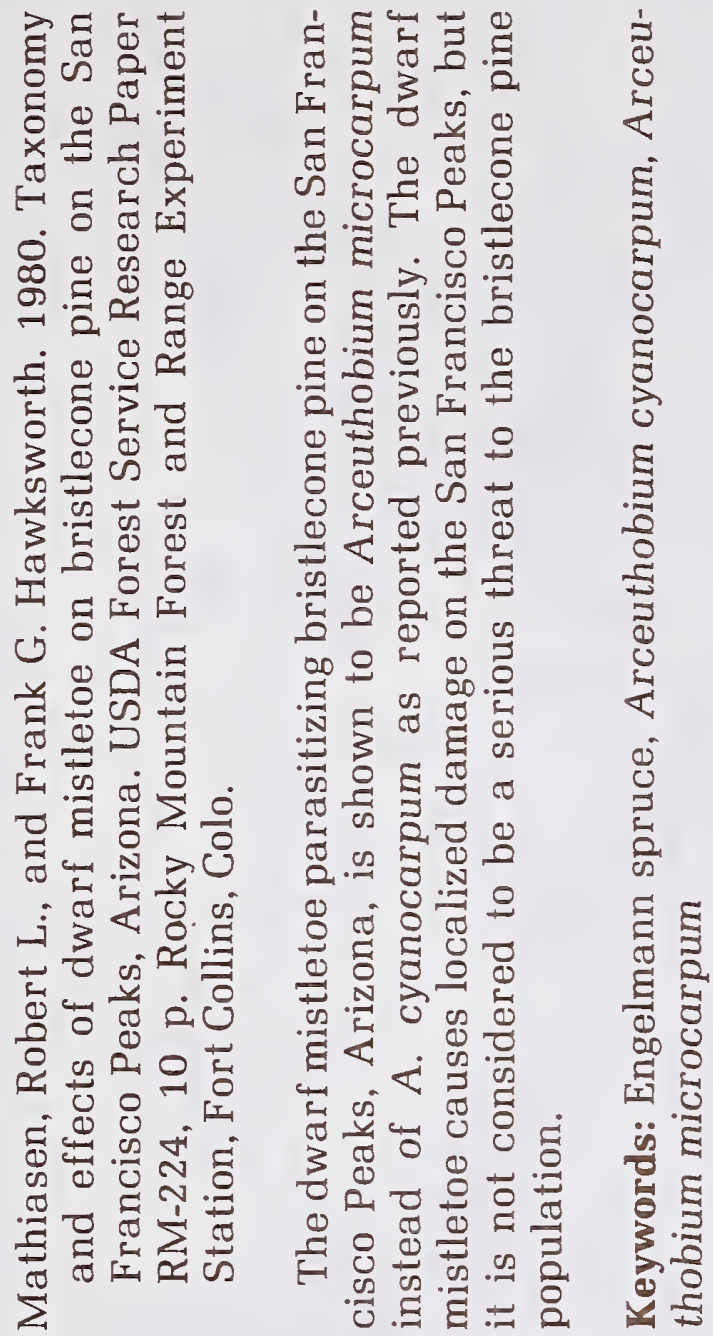

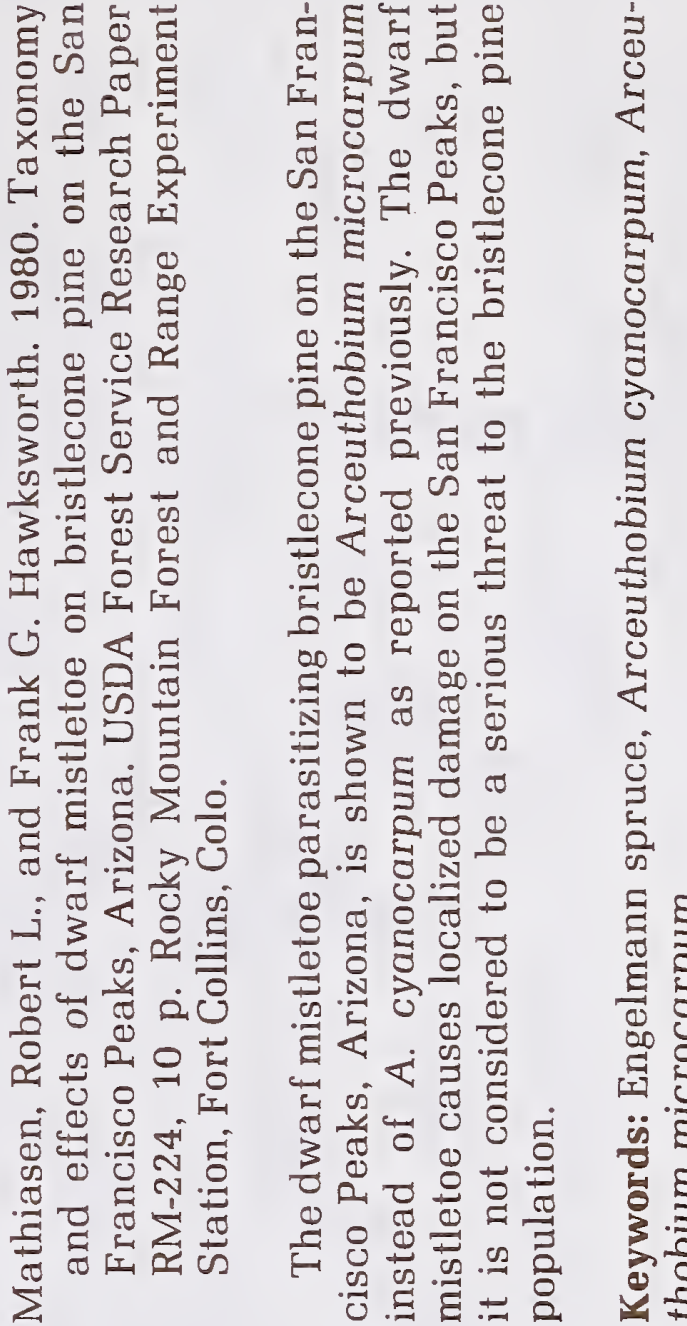

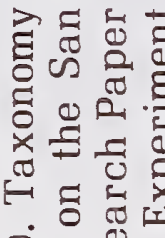

○ं ¿ 0.0

동루일

30 成

उ. कू

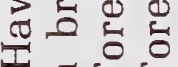

도도

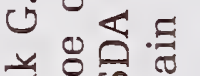

苋氞焉

营苋总

ซี छี

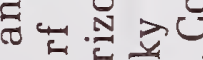

的安若

$=30$

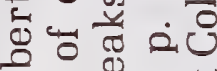

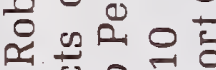

¿ 0

ฮี่

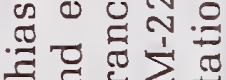

촣ำ

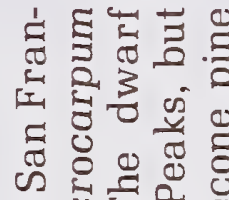

记

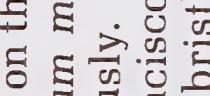

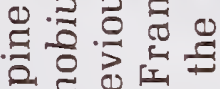

논

워

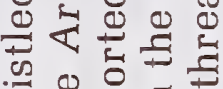

范节

$\infty 020$.

:

"

象. 융

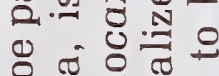

융

.

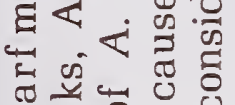

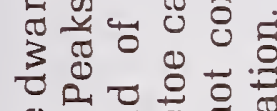

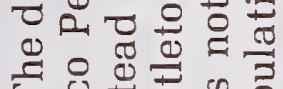

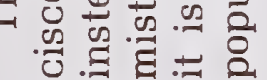

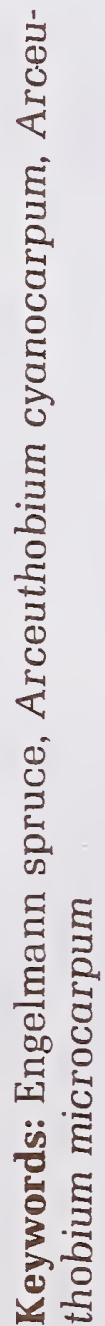

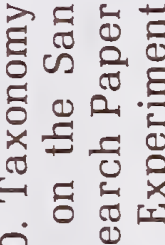

○ं

品. こ

요 0

苍焉

需的

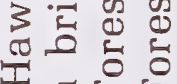

동도

نㄴ․․

光苞点

踏远

흐 륭

ฮี

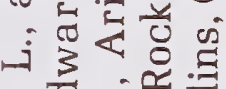

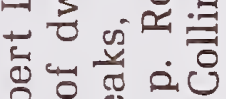

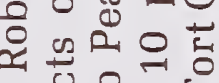

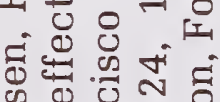

D.

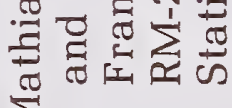

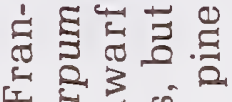

I

๙ี

巳.

ธ도월

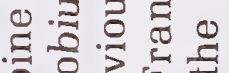

도ㅇㅝㅗ

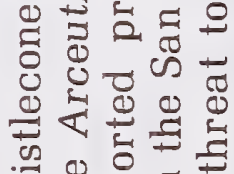

응융 명

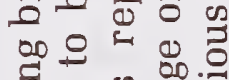

.

ซ

क क 0 \%

응 응

잉

ज्ञ

घ < $<$ 号

तี

उ

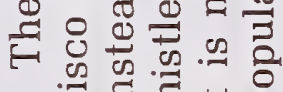

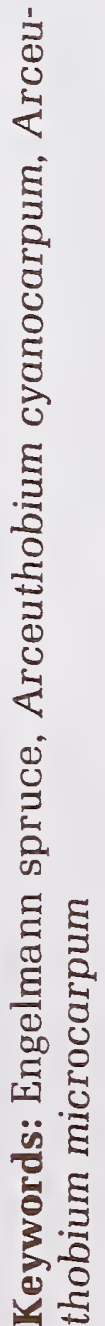




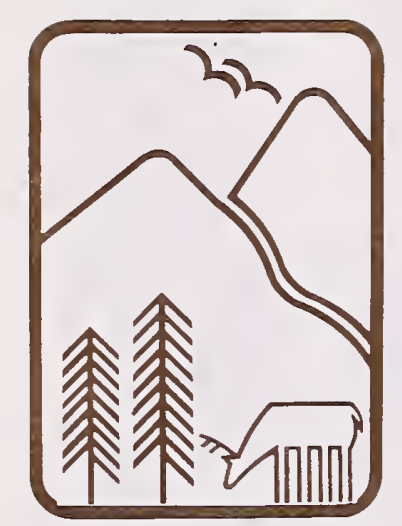

Rocky

Mountains
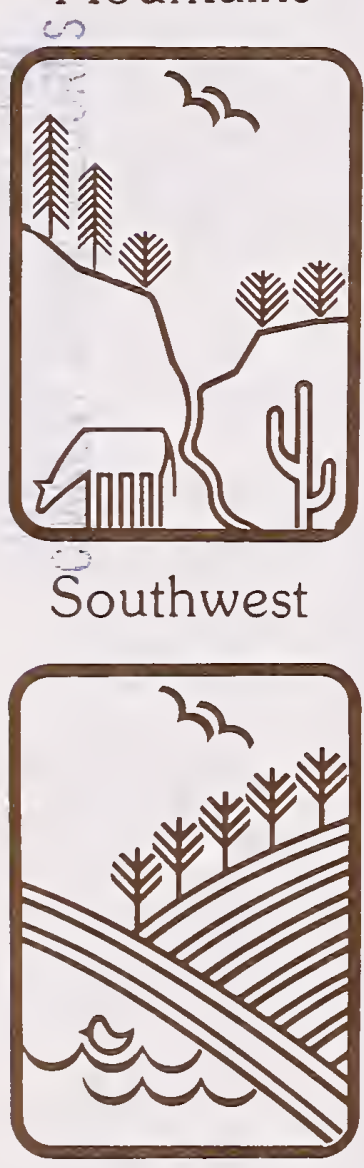

Great Plains
U.S. Department of Agriculture Forest Service

\section{Rocky Mountain Forest and Range Experiment Station}

The Rocky Mountain Station is one of eight regional experiment stations, plus the Forest Products Laboratory and the Washington Office Staff, that make up the Forest Service research organization.

\section{RESEARCH FOCUS}

Research programs at the Rocky Mountain Station are coordinated with area universities and with other institutions. Many studies are conducted on a cooperative basis to accelerate solutions to problems involving range, water, wildlife and fish habitat, human and community development, timber, recreation, protection, and multiresource evaluation.

\section{RESEARCH LOCATIONS}

Research Work Units of the Rocky Mountain Station are operated in cooperation with universities in the following cities:

Albuquerque, New Mexico

Bottineau, North Dakota

Flagstaff, Arizona

Fort Collins, Colorado*

Laramie, Wyoming

Lincoln, Nebraska

Lubbock, Texas

Rapid City, South Dakota

Tempe, Arizona

*Station Headquarters: 240 W. Prospect St., Fort Collins, CO 80526 